\title{
Predictive value of early developmental examination
}

\author{
ROSEMARY BOOTHMAN, ELIZABETH MACCALLUM WHITE, and SANDRA SWEENIE \\ From the Social Paediatric and Obstetric Research Unit, Department of Child Health, \\ University of Glasgow and Greater Glasgow Health Board
}

\begin{abstract}
Boothman, R., White, E. M., and Sweenie, S. (1976). Archives of Disease in Childhood, 51, 430. Predictive value of early developmental examination. A developmental examination was carried out on 168 children at intervals over a 3year period. The results suggest that developmental screening of this type is effective in picking out the 'poor performers' who might well benefit from preschool education and extra health visitor supervision. On the other hand, the test given to children under the age of one year failed to pick out 2 children who were found to be moderately handicapped at the time of the 3-year examination. The study underlined some of the problems of universal screening which require further research, and the need to assess the results of developmental screening clinic.
\end{abstract}

The benefits to both the handicapped child and his parents resulting from early detection, and thus early management and treatment, have been stressed by a number of workers (Loring, 1971). This has been put forward as an argument in favour of developmental examination of all infants (Egan, Illingworth, and MacKeith, 1971) and has led to the setting up of clinics for the purpose. It is, however, surprising that there has been no comprehensive examination of the effectiveness of current screening procedures in detecting handicaps in view of the continuing doubts about the predictive value of early developmental examination. Tests used today are mainly abridgements of the original psychological tests used for full developmental assessment, and the use of such abridgements has been blamed for the inconsistent predictions obtained by a number of reputable workers (Illingworth, 1960). Failure to resolve these doubts imposes serious limitations on any workable screening programme. A brief pilot study on effectiveness of a 'screening' clinic' has been published (Meadow and Keating, 1970) and has shown encouraging preliminary results. In the first year of its operation developmental defects were detected twice as often as in the previous year in the 'ordinary clinic'. It was accepted that the findings did not take account of the nature of the handicaps detected nor whether they had been previously undiagnosed. More detailed follow-up studies are required to substantiate or refute this initial encouraging impression.

Received 12 September 1975.
The study was conducted in two parts. In the first part emphasis was placed on determining whether development of apparently normal infants was affected in any way by the course of events during the perinatal period. No such effect was detected (White, 1973). We now report a study of the same cohort at 3 years of age. The aim of the combined studies was to compare the developmental findings at the different age levels to assess their predictive value within the group and in relation to the individual child.

\section{Materials and methods}

The cohort consisted of 168 children in the 4 maternity units of the City of Glasgow during the period of the selection. Children weighing $<2.04 \mathrm{~kg}\left(4 \frac{1}{2} \mathrm{lb}\right)$ or of $<36$ completed weeks' gestation were excluded from the study, as were children with major handicaps, and illegitimate infants. Difficulties in tracing and following these groups at the appropriate ages during a preliminary pilot study led to their exclusion.

At the end of the first year 155 children remained in the study and at the age of 3 years 124 were traced. Two families elected not to continue with the study owing to altered family circumstances, so that a total of 122 children was ultimately followed up. All examinations in the first year were undertaken by one author (E.W.). The follow-up at 3 years was done by another (R.B.).

In the first year the children were seen in their homes at 4 weeks, 16 weeks, 28 weeks, and 52 weeks. During this period a single proforma was used and the items tested were arranged in ascending complexity. The tests were drawn from the Developmental Schedules of Gesell and Armatruda (1947), Illingworth (1962), 
and Sheridan (1971) as described by White (1973). For the 3-year-old examination a proforma was compiled from the tests suggested by Illingworth (1962), Griffith (1954), and Egan, Illingworth, and Mac Keith (1971). The tests were selected from a large battery used in the preliminary pilot study. The four fields of development were tested individually at all examinations. In the first analysis no extra value was obtained by examining these separately. The results were therefore based on total scores. A frequency distribution of the total scores obtained by each child was constructed (Fig. 1).

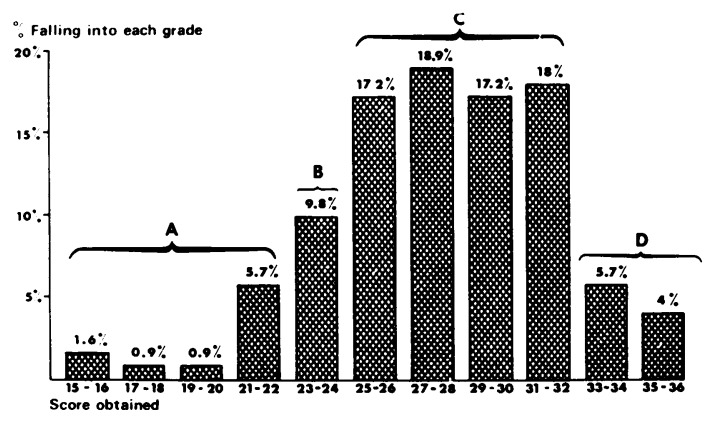

FIG. 1.-Histogram showing the method by which the scores obtained by the 122 children were used to divide them into four grades of performers.

At the 3-year examination the scores were insufficiently spread to allow standard centile definition. The histogram was therefore arbitrarily divided into four grades of performance. (A) Poor performancefurther investigation required $9 \%$. (B) Borderline performance-to be reviewed again $10 \%$ (C) Satisfactory performance-no further action $71 \%$. (D) A bove average for age $10 \%$. In the first year of the review a much greater spread of scores was obtained. For purposes of comparison the percentages of the sample falling into four grades at 3 years were applied to the scores of children at each age level up to one year of age. No particular problems were encountered in administering and scoring the items in the first part of the study. However, at the 3-year-old examination difficulties were encountered because of the reticence natural to this age, and resulted in the need to accept mother's history for many items.

The field most affected was 'gross motor activity', because children who had been reared in tenement flats proved to be too frightened of stairs to get any worthwhile estimate of their ability to ascend and descend. Difficulties were also encountered in getting the children to try standing on one foot or jumping, and in the final analysis gross motor activity had to be excluded because of the unacceptable number of 'don't know' answers.

The field which proved easiest to evaluate was 'fine motor activity' because all items relied on observation. 'Social development', on the other hand, was entirely dependent on the mother's history, while 'speech-andlanguage' was in many cases a combination of history and mother's statement during the examination. In the areas where mother's history was relied upon a score of 1 was awarded to items reported to be within the capabilities of the child, while a score of 2 was given when items were actually observed.

\section{Results}

The predictive value of developmental milestones can be important either in group predictions or in relation to individual children. Both these aspects were looked at in this study.

Predictive value related to group findings. Fig. 2 traces the course of children falling into grade $A$ or D at the age of 4 weeks, 52 weeks, and 3 years. It will be noted that at the 4 weeks' examination the findings bore little or no relation to subsequent progress. At all other ages variations in performance were uncommon, with grade $A$ performers staying below and grade $D$ performers remaining well above the mean for the group throughout the study. As expected, the best correlation was found between sequential examinations, though this was more marked between 16 weeks and 40 weeks than subsequently.

Predictions in relation to the individual. Detection of handicap. At the end of the first part of the study one child was under review because of possible strabismus but no other handicaps were detected. When the group was seen again at the age of 3 years a number of disorders of varying degrees of significance was noted. 2 children (Case 1, Case 2) (Fig. 3) were considered to be definitely abnormal and in both cases this impression was substantiated by formal assessment.

Case 1. This child was extremely ataxic and failed all tests of manual adaptability presented to him. Despite reasonatle social development his 'speech-andlanguage' score fell well outside the normal for the group. Since the 52-week examination this child had developed grand mal epilepsy and ataxia unrelated to drug therapy, and upon investigation the presence of some degree of handicap was recognized. At the time of the 3-year-old follow-up he was being seen at regular intervals at the Developmental Assessment Centre, but a decision reregarding school placement had not been made.

Case 2. In this child the field most affected was 'speech-and-language'. She pointed to objects but did not have any understandable words. As in Case 1, more than one field was affected, and she performed poorly in both social and manual adaptability tests. The presence of retardation had not been suspected and the parents refused to accept that there was anything wrong with the child. However, they did attend the Developmental Assessment Centre on one occasion when a diagnosis of 'handicap-degree unknown' was recorded. 


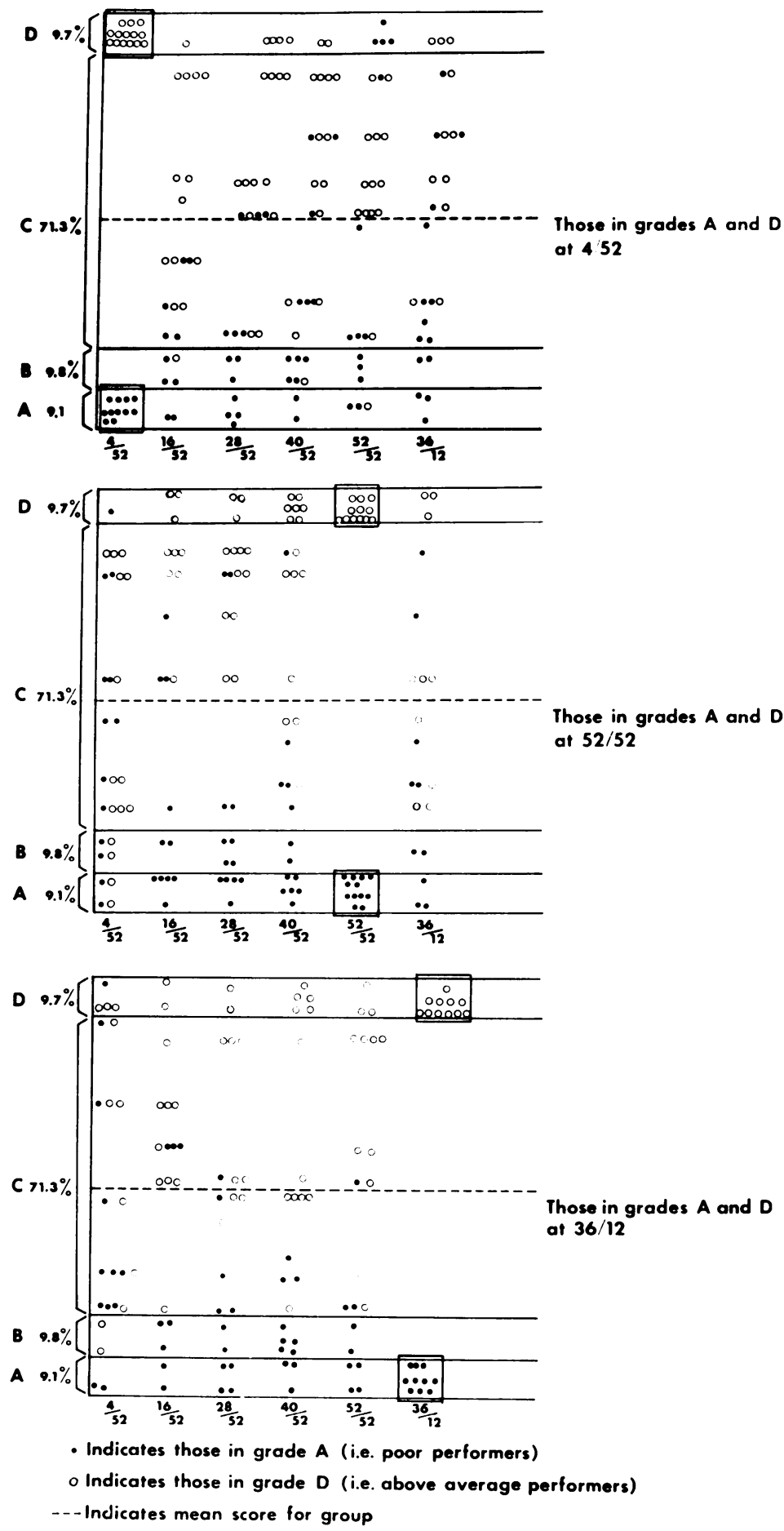

FIG. 2.-Scattergram showing the course followed by children whose scores were at the upper or lower ends of the distribution curve, at either 4 weeks, 52 weeks, or 36 months. indicates those in grade $A$ (poor performers); $\bigcirc$ indicates grade $D$ (above average performers; - - mean score for group. 


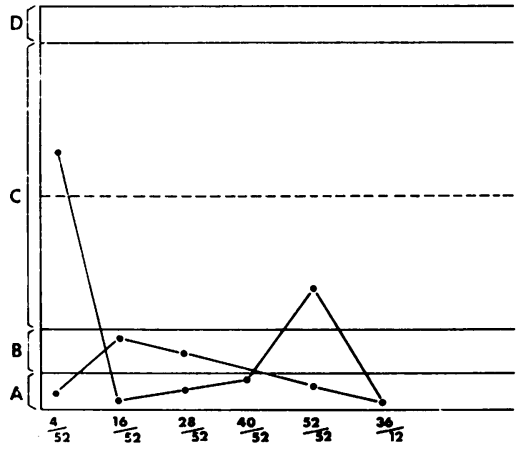

FIG. 3.-Course followed by 2 children regarded as abnormal at 36 months, showing fluctuations in performance over the study period.

A decision about school placement could not be made on a single visit but the author's impression was that special education would be required.

Less severe deviations from normality occurred in 7 cases. 3 children had developed convulsions, squints had become obvious in 2 others, congenital dislocation of the hips had been detected in one boy after an accident, and another child was attending an orthopaedic clinic because of hemihypertrophy. In the case of the 3 children with convulsions, their progress throughout the study was traced in detail but the incidents did not appear to affect development. The numbers involved were too small to reach statistical significance, but the 3 children did not appear to differ in any way from the rest of the sample.

Deterioration in performance. 4 children appeared to be doing well up to 28 weeks and then performance deteriorated (Fig. 4). Factors which

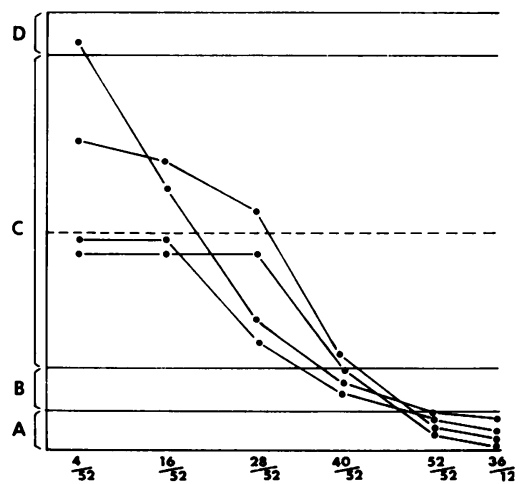

FIG. 4.-Deteriorating course followed by 4 children from a level considered normal at 28 weeks (grade $C$ ) to a poor performance level (grade $A$ ) at 36 months. could have precipitated this fall were examined. While the numbers involved were too small to be of statistical significance, it is interesting to note that 3 of the 4 children were from social class $V$, as compared with 34 out of the total of 168 . Another factor which might well have prejudiced their progress was the fact that one mother became pregnant again during the study while another had a hysterectomy for carcinoma during the same period. Thus, 2 out of the 4 children were potentially deprived of maternal care at a vital stage in development. 3 children who came into grade $\mathrm{C}$ at the age of 3 years had been in either Grade A or $B$ during the first year. Environmental factors were again examined. These children did not differ from the rest of the sample except for the fact that the family size was above the mean for the group. One could postulate that these children were at an age to benefit from the stimulation of older members of the family.

\section{TABLE}

Items assessed at 3 years of age (score: mother's history 1; observation 2)

\begin{tabular}{|c|c|}
\hline $\begin{array}{l}\text { Gross motor } \\
\text { Gait normal } \\
\text { Stands on one foot unsupported } \\
\text { Goes up and down stairs } \\
\quad \text { (abandoned after pilot study) }\end{array}$ & $\begin{array}{l}\text { Fine motor } \\
\text { Builds tower of } 9 \text { cubes } \\
\text { Makes train } \\
\text { Imitates circle } \\
\text { Imitates cross } \\
\text { Puts } 10 \text { pellets in cup in } \frac{1}{2} \\
\text { minute } \\
6 \text { shape form board }\end{array}$ \\
\hline $\begin{array}{l}\text { Speech and language } \\
\text { Obeys instructions from } 10 \\
\text { feet away } \\
\text { Points to nose, eyes, mouth } \\
\text { Gives first name } \\
\text { Gives sex } \\
\text { Gives age }\end{array}$ & $\begin{array}{l}\text { Social } \\
\text { Uses cup } \\
\text { Uses spoon } \\
\text { Uses fork } \\
\text { Dresses self (except buttons, } \\
\quad \text { laces) } \\
\text { Plays meaningfully with toys } \\
\text { Dry by day } \\
\text { Dry by night } \\
\text { Clean day and night }\end{array}$ \\
\hline
\end{tabular}

\section{Discussion}

The findings of this study show that from the age of 28 weeks a fairly reasonable prediction of developmental progress to the age of 3 years was obtained. The lack of correlation between the 4 weeks' examination and subsequent development is not really surprising in the light of Drillien's findings regarding the large variety of neurological signs present at this age which were of no significance later (Drillien, 1972). The findings do, however, question the advisability of using 6 weeks as an age for initial developmental screening. Undoubtedly, one would expect that very many fewer spurious neurological signs would be present at 6 weeks than 
at 4 weeks, but if 'term' is taken to include a gestational age of 37 weeks and over, then a large number of children will be at a developmental age of only 3 to 4 weeks if the first examination is done at 6 weeks. Unfortunately, the children in this study were not seen at 12 weeks but there seems to be a case for using this age for the first developmental screening examination. This proposal of course depends on the assumption that all neonates will have an examination before discharge from the unit in which they were born.

The consistency of the pattern of performance of the group seems to indicate that developmental progress in the first year of life does in fact give a reasonable estimate of later achievements. With regard to individual predictions it is disappointing that Cases 1 and 2 were not suspected of being abnormal during the first year of the study. This may have arisen because no handicap was present in the first year or because the tests were not suffciently 'sensitive' or 'specific' to distinguish between the 'low normal' and the 'definitely abnormal'. A review of the scores obtained by the 2 children in the first year suggests that problems were present in both cases from an early stage (Fig. 3). It is difficult though to see at what point either child could have been diagnosed as being definitely abnormal in the first year. However, the course followed by both should have marked them as children in need of follow-up in any ongoing screening programme.

It is interesting that in 4 children whose performance deteriorated from the 28-week level adverse environmental factors were operating from this age. Routine developmental screening might well prove to be a useful aid to the diagnosis of early environmental deprivation if these findings are corroborated by other studies.

Criticism could be levelled at the study because different observers were used in the first year and the third year of the follow-up. The change was, however, considered to be realistic, as no one observer is likely to screen the same child over a long period. This aspect of screening needs to be further examined. The results of this study might be expected to be more reliable than would be the case in practice because the tests were sheltered from the limits of time in a busy clinic, and furthermore they were performed in a research atmosphere. Despite these disadvantages, the study spotlights some of the problems likely to be met in an ongoing screening programme and also emphasizes the need of evaluation of results from clinics which are already in operation.

We thank all who participated in this study, especially the children and their parents, for continued co-operation; Professor I. D. G. Richards, Professor J. H. Hutchison, and Dr. J. P. Stanfield for help and advice; and the Department of Medical Illustration at the Royal Hospital for Sick Children for the production of the diagrams.

The study was supported by generous grants from the National Children's Fund and the Scottish Home and Health Department.

\section{REFERENCES}

Drillien, C. M. (1972). Abnormal neurological signs in the first year of life in low-birthweight infants: possible prognostic significance. Developmental Medicine and Child Neurology, 14, 575.

Egan, D. F., Illingworth, R. S., and Mac Keith, R. C. (1971) Developmental screening 0-5 years. Clinics in Developmental Medicine, no. 30. Spastics Society and Hetnemann, London.

Gesell, A., and Armatruda, C. S. (1947). Developmental Diagnosis, 2nd ed. Hoeber, New York.

Griffith, R. (1954). The Abilities of Babies. University of London Press, London.

Illingworth, R. S. (1960). The Development of the Infant and Young Child-Normal and Abnormal. Livingstoñe, Edinburgh and London.

Illingworth, R. S. (1962). An introduction to developmental assessment in the first year. Clinics in Developmental Medicine, no. 3. Spastics Society and Heinemann, London.

Loring, J. (1971). (ed.) The Children Who Cannot Wait. Spastics Society, London.

Meadow, J. G., and Keating, P. K. H. (1970). A pilot scheme in developmental screening clinics. Medical Officer, 124, 270.

Sheridan, M. D. (1971). Stycar charts for babies 1 month to 1 year. Health Trends, 3, 60.

White, E. M. (1973). A domiciliary assessment of child development. M.D. thesis, Edinburgh University.

Correspondence to Dr. R. Boothman, Social Paediatric and Obstetric Research Unit, 112 Ingram Street, Glasgow G1 1RN. 